\title{
The Prevalence and Analysis of Risk Factors for Postpartum Anemia in Women Without Prepartum Anemia
}

\author{
Betül Dündar, $@$ Burcu Dinçgez Çakmak
}

Department of Obstetrics and Gynecology, University of Health Sciences, Bursa Yuksek Ihtisas Training and Research Hospital, Bursa, Turkey

\begin{abstract}
Introduction: Postpartum anemia is a significant and common public health issue. Here, the prevalence of postpartum anemia and predisposing factors in women without prepartum anemia was investigated.

Methods: This retrospective study was conducted between February 2018 and April 2018 with 1013 patients without prepartum anemia. Sociodemographic features, delivery characteristics, and hemoglobin levels of the patients were recorded. Variables were compared between the anemic and nonanemic groups, independent predictors were determined, and risk score for postpartum anemia was calculated.

Results: The rate of cesarean section and emergent cesarean, the frequency of episiotomy and perineal laceration, and the application of general anesthesia were higher, whereas mean gestational week at birth and the ratio of active management of the third stage of labor were lower in the anemic group. In regression analysis, episiotomy (odds ratio (OR) 5.45, 95\% confidence interval (Cl) 3.75-7.93, $\mathrm{p}<0.001)$, perineal laceration (OR 7.09, 95\% Cl 2.88-17.47, $\mathrm{p}<0.001)$, active management (OR 0.09, 95\% Cl 0.06-0.12, p<0.001), general anesthesia (OR 3.9, 95\% Cl 0.99-15.32, p=0.026), and emergent cesarean (OR 19.35, $95 \% \mathrm{Cl} 10.57-35.41, \mathrm{p}<0.001)$ were found to be significant independent predictors. The formula of risk score calculated to determine patients who were under risk to develop postpartum anemia was as follows: risk score $=(5 \times$ episiotomy $)+(7 \times$ perineal laceration)+(3xgeneral anesthesia)+(19xemergent cesarean)-(11xactive management). Risk score $>-4$ was found to be a predictor for postpartum anemia with a sensitivity of $73.7 \%$ and specificity of $81.1 \%$, and it increases the risk of postpartum anemia approximately 12 times.

Discussion and Conclusion: The prevalence of postpartum anemia is quite high in our clinic, and so a non-selective screening program for postpartum anemia could be applicable. However, determining patients under high risk is still important to be alert to prevent short- and long-term morbidities.
\end{abstract}

Keywords: Anemia; postpartum; prevalence; risk factors; risk score.

Postan ostpartum anemia is defined as a hemoglobin $(\mathrm{Hb})$ concentration $<11 \mathrm{~g} / \mathrm{dl}$ at 1 week of postpartum and $<12 \mathrm{~g} / \mathrm{dl}$ at 8 weeks of postpartum ${ }^{[1]}$. Since $20 \%$ of all maternal deaths occurring each year were known to be due to peripartum bleeding and anemia, it is a significant public health issue ${ }^{[2-4]}$. Anemia is quite common among women in the postpartum period and is found to be as frequent as $22 \%-30 \%[5,6]$. This prevalence is highest in developing countries and reaches $70 \%-80 \%{ }^{[1,7]}$. Despite its high prevalence, postpartum anemia may not be diagnosed on time, and in addition to its severe short-term morbidities, it is even reported to be associated with severe long-term

Correspondence (İletişim): Burcu Dinçgez Çakmak, M.D. Sağlık Bilimleri Üniversitesi, Bursa Yuksek Ihtisas Egitim ve Arastirma Hastanesi, Kadin Hastaliklari ve Dogum Klinigi, Bursa, Turkey

Phone (Telefon): +90 5305448828 E-mail (E-posta): burcumavis@gmail.com

Submitted Date (Başvuru Tarihi): 02.11.2018 Accepted Date (Kabul Tarihi): 11.02.2019

Copyright 2019 Haydarpaşa Numune Medical Journal

OPEN ACCESS This is an open access article under the CC BY-NC license (http://creativecommons.org/licenses/by-nc/4.0/) 
morbidities. In a study investigating the long-term effects of early postpartum anemia, it was stated as an independent risk factor for long-term atherosclerotic events ${ }^{[8]}$.

The major causes of postpartum anemia are prepartum iron deficiency anemia and excessive blood loss during delivery ${ }^{[1,6]}$. Although women suffering from anemia after delivery are most of the time symptomatic, symptoms, such as tiredness, breathlessness, palpitations, dizziness, and decreased physical endurance, are underestimated, and they are generally considered to be associated with new and challenging lifestyle of motherhood after the arrival of the newborn. However, postpartum anemia may be a troublesome condition since these physical symptoms may cause a tendency to develop cognitive problems and psychiatric disorders ${ }^{[9]}$. Therefore, anemia should be recognized as a problem as soon as possible at the postpartum period and should be treated properly during pregnancy and in puerperium to avoid severe short- and long-term consequences.

At this point, the question whether screening for postpartum anemia is required or not arises. This is still controversial ${ }^{[10,11]}$. The Centers for Disease Control and Prevention advices selective screening for anemia at 4-6 weeks of postpartum in women who had anemia throughout the 3rd trimester or had multiple gestations or in those who experienced intrapartum excessive blood loss ${ }^{[12,13]}$. However, non-selective screening may be an option. Although there have not been any cost-effectivity studies yet, complete blood count $(C B C)$ is not an expensive test, and especially in countries where postpartum anemia is frequent, non-selective screening may not be very expensive ${ }^{[12]}$.

In our country, the Ministry of Health recommends $\mathrm{Hb}$ measurement at $6 \mathrm{~h}$ of postpartum for anemia screening [14]. Patients are routinely discharged from birth clinics at $24 \mathrm{~h}$ of postpartum in case of uncomplicated deliveries and $48 \mathrm{~h}$ in case of cesarean section $(\mathrm{C} / \mathrm{S})$. $\mathrm{Hb}$ measurement is repeated prior to discharge.

In the present study, the anemia status of women without prepartum anemia at the postpartum period was analyzed, and the prevalence of postpartum anemia and predisposing factors was investigated. We believe that determining the risk factors for postpartum anemia will be helpful in optimizing the efforts to prevent, to detect, and to treat anemia during the postpartum period.

\section{Materials and Methods}

This was a cross-sectional retrospective study that was conducted in a university-affiliated tertiary research and train- ing hospital. A total of 2732 patients gave birth in our clinic between February 1, 2018 and April 30, 2018. After exclusion of patients with prepartum anemia, 1245 patients were included in the study. Preterm deliveries, gestational diabetes, preeclampsia, multiple gestations, placental adhesion disorders, and instrumental deliveries (forceps or vacuum) were excluded, and then 1013 patients were analyzed.

Patients' age, gravidity, parity (multiparous or primiparous), gestational age at birth, mode of delivery (vaginal, elective $C / S$, or emergency $C / S$ ), initiation of labor (spontaneous or induction), birth weight of newborn, type of anesthesia (spinal or general), presence of episiotomy, presence of perineal laceration, mode of placental delivery (spontaneous or active management), and $\mathrm{Hb}$ levels were recorded.

In our clinic, for vaginal deliveries, mediolateral episiotomy was routinely performed, and following delivery, postpartum anemia was routinely investigated through $C B C$ by analyzing venous blood samples of the patients at $6 \mathrm{~h}$ of postpartum (Mindray Bio-Medical Electronics Co., Ltd., Shenzhen, China). Anemia was accepted as $\mathrm{Hb}<11 \mathrm{~g} / \mathrm{dl}$ as it was defined in the Postpartum Management Guideline of the Turkish Ministry of Health.

In our study, active management of placental delivery was defined as the interventions including application of uterotonic medications simultaneously with controlled traction of the umbilical cord for placental extraction after delivery of the fetus.

In our country, ethics committee approval is unnecessary for retrospective studies. Our study was conducted in accordance with the Declaration of Helsinki.

\section{Statistical Analysis}

Statistical data were analyzed using SPSS (released 2012, IBM SPSS Statistics for Windows, version 21.0; IBM Corp. Armonk, NY, USA). A $p$ value of $\leq 0.05$ was considered as statistically significant. Shapiro-Wilk test was used to assess whether the variables followed normal distribution or not. Data were expressed as mean \pm standard deviation for normally distributed variables and as median (min-max) for non-normally distributed variables. For continuous variables, Mann-Whitney $U$ test was used for between group comparisons. For categorical variables, chi-square test was used for comparison and expressed as frequencies and percentages. Logistic regression analysis was performed to assess the independent predictors of postpartum anemia. Variables included in logistic regression model were onset of labor with induction, emergent $C / S$, presence of 
mediolateral episiotomy, presence of perineal lacerations, active management of placental delivery, and birth weight. Variables were analyzed in logistic regression model by using the Enter Method to determine the risk factors. The variables found to be significant in the model were determined as independent risk factors. A $p$ value of $<0.001$ was considered as statistically significant for logistic regression analysis. By using independent risk factors, a risk score was calculated. A receiver operating characteristic (ROC) analysis was performed to determine a cut-off point for the risk score.

\section{Results}

A total of 1245 patients without prepartum anemia gave birth in our clinic between February 1, 2018 and April 30, 2018. After excluding patients with preterm deliveries, gestational diabetes, preeclampsia, multiple gestations, placental adhesion disorders, instrumental deliveries, and unavailable data, 1013 patients were analyzed. The prevalence of anemia was $45.11 \%(n=457)$. The mean age of the study group was $26.96 \pm 6.16$ years. Median gravidity was $2(1-10)$, and median parity was $1(0-8)$. Mean gestational week at birth was $38.24 \pm 2.33$ weeks, and mean birth weight was $3139.48 \pm 582.8 \mathrm{~g}$. A total of 274 (27.05\%) patients were prim- iparous. The rate of $C / S$ was $23.1 \%(n=234)$, and the rate of normal vaginal delivery was $76.9 \%(n=779)$. In 588 (58.05\%) patients, labor started spontaneously, $341(43.77 \%)$ of these patients had episiotomy, and 36 (4.62\%) of these patients had third- or fourth-degree perineal laceration.

The sociodemographic features and delivery characteristics of the patients are shown in Table 1. There was no difference between patients who had anemia and those who do not with regard to age, gravidity, parity, the onset of labor, and birth weights. Among patients with anemia, the rate of $C / S(p=0.044)$, the frequency of episiotomy $(p<0.001)$ and perineal laceration $(p<0.001)$, the rate of emergent $C / S(p<0.001)$, and the application of general anesthesia $(p<0.001)$ were higher, whereas the mean gestational week at birth $(p=0.002)$ and active management of placenta $(p<0.001)$ were lower.

In multivariate regression analysis, episiotomy (odds ratio (OR) 5.45, 95\% confidence interval (Cl) 3.75-7.93, $\mathrm{p}<0.001$ ), perineal laceration (OR 7.09, 95\% Cl 2.88-17.47, $\mathrm{p}<0.001)$, active management (OR $0.09,95 \% \mathrm{Cl} 0.06-0.12, \mathrm{p}<0.001)$, general anesthesia (OR 3.9, 95\% Cl 0.99-15.32, $\mathrm{p}=0.026$ ), and emergent $\mathrm{C} / \mathrm{S}$ (OR 19.35, 95\% Cl 10.57-35.41, $\mathrm{p}<0.001$ ) were found to be significant independent predictors of postpartum anemia (Table 2).

Table 1. Sociodemographic features and delivery characteristics of patients

\begin{tabular}{|c|c|c|c|}
\hline & Anemic $(n=457)$ & Non-anemic $(n=556)$ & $\mathbf{p}$ \\
\hline Age (years) & $26.91 \pm 6.22$ & $26.99 \pm 6.11$ & 0.815 \\
\hline Gravida (n) & $2(1: 10)$ & $2(1: 7)$ & 0.498 \\
\hline Parity (n) & $1(0: 8)$ & $1(0: 6)$ & 0.947 \\
\hline \multicolumn{4}{|l|}{ Delivery mode (n,\%) } \\
\hline Normal & $338(73.96)$ & $441(79.32)$ & 0.044 \\
\hline Cesarean section & $119(26.04)$ & $115(20.68)$ & \\
\hline Gestational age at delivery (week) & $38.04 \pm 2.41$ & $38.40 \pm 2.24$ & 0.002 \\
\hline Birth weight (g, \%) & & & 0.656 \\
\hline$<2500$ & $54(11.82)$ & $58(10.43)$ & \\
\hline $2501-4000$ & $380(83.15)$ & $474(85.25)$ & \\
\hline$>4000$ & $23(5.03)$ & $24(4.32)$ & \\
\hline Spontaneous onset of labor (n,\%) & $268(58.64)$ & $320(57.55)$ & 0.585 \\
\hline Presence of episiotomy (n,\%) & $234(51.20)$ & 107(19.24) & $<0.001$ \\
\hline Perineal laceration (n,\%) & $30(6.5 \%)$ & $6(1.08)$ & $<0.001$ \\
\hline \multicolumn{4}{|l|}{ Delivery of placenta $(n, \%)$} \\
\hline Spontaneous & $293(64.11)$ & 85 (15.29) & $<0.001$ \\
\hline Active management & $164(35.89)$ & $471(84.71)$ & \\
\hline \multicolumn{4}{|l|}{ Mode of anesthesia $(n, \%)$} \\
\hline Spinal & $79(17.29)$ & $96(17.27)$ & $<0.001$ \\
\hline General & $41(8.97)$ & $18(3.24)$ & \\
\hline Emergent cesarean section ( $n, \%)$ & $54(11.82)$ & $21(3.78)$ & $<0.001$ \\
\hline Prepartum haemoglobin (g/dl) & $11.8 \pm 1.2$ & $12.3 \pm 1.9$ & 0.516 \\
\hline
\end{tabular}


Table 2. Logistic regression analysis for predicting postpartum anemia

\begin{tabular}{lcccc}
\hline & $\mathbf{p}$ & Odds ratio & \multicolumn{2}{c}{$\mathbf{9 5 \%}$ Confidence interval } \\
\cline { 4 - 5 } & & & Lower & Upper \\
\hline Mode of delivery & 0.369 & 1.49 & 0.63 & 3.52 \\
Presence of episiotomy & $<\mathbf{0 . 0 0 1}$ & 5.45 & 3.75 & 7.93 \\
Perineal laceration & $<\mathbf{0 . 0 0 1}$ & 7.09 & 2.88 & 17.47 \\
Active management of placenta & $<\mathbf{0 . 0 0 1}$ & 0.09 & 0.06 & 0.12 \\
General anesthesia & $\mathbf{0 . 0 2 6}$ & 3.90 & 0.99 & 15.32 \\
Emergent cesarean section & $<\mathbf{0 . 0 0 1}$ & 19.35 & 10.57 & 35.41 \\
Gestational age at delivery & 0.367 & 0.97 & 0.91 & 1.04 \\
\hline
\end{tabular}

Table 3. The table of receiver operating curve for the risk score to predict postpartum anemia

\begin{tabular}{ccccc}
\hline & OR & p & Sensitivity (\%) & Specificity (\%) \\
\hline Risk score $>-4$ & 12.06 & $<0.001$ & 73.7 & 81.1 \\
\hline
\end{tabular}

The risk score was calculated using the OR to determine patients who were under risk to develop postpartum anemia. The formula was as follows: risk score $=(5 \times e p i-$ siotomy $)+(7 \times$ perineal laceration $)+(3 \times$ general anesthesia)+(19xemergent $\mathrm{C} / \mathrm{S})-(11 \times$ active management). According to ROC analysis, risk score $>-4$ was found to be a predictor for postpartum anemia with a sensitivity of $73.7 \%$ and specificity of $81.1 \%$ (Fig. 1, Table 3). Moreover, we found that risk score $>-4$ increases the risk of postpartum anemia approximately 12 times.

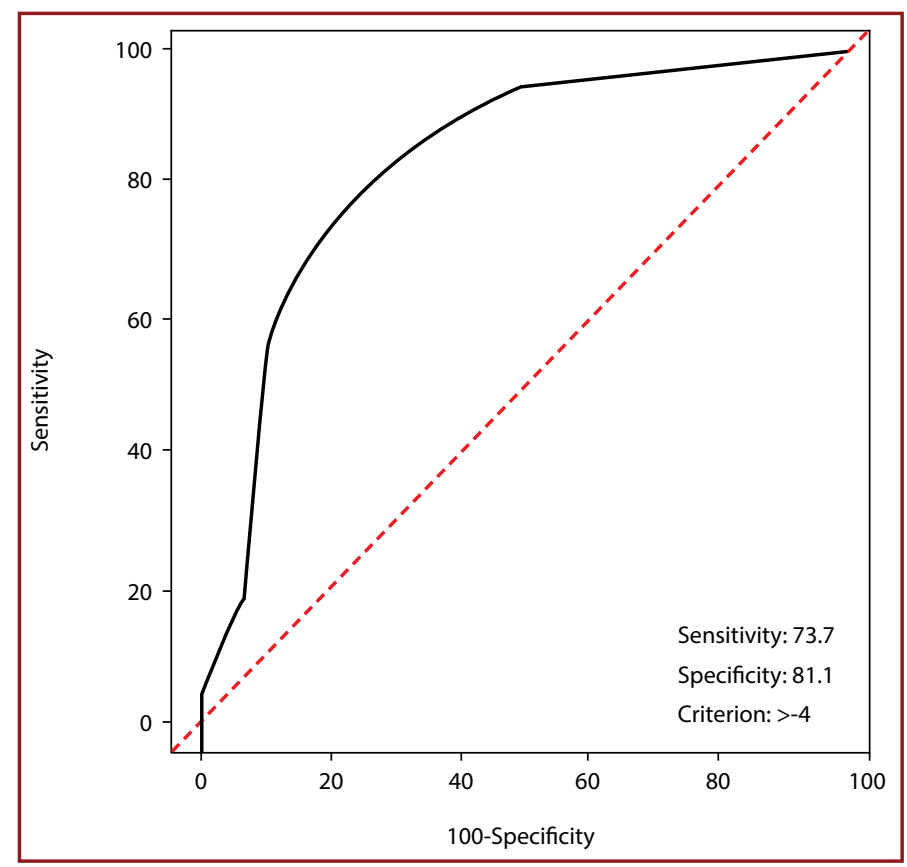

Figure 1. Receiver operating curve for the risk score to predict postpartum anemia.

\section{Discussion}

The main findings of the study were as follows: (1) the prevalence of anemia was $45.11 \%$, (2) the rate of $C / S$, the frequency of episiotomy and perineal laceration, the rate of emergent $C / S$, and the application of general anesthesia were higher, whereas the mean gestational week at birth and active management of placenta were lower in the anemic groups, (3) episiotomy, perineal laceration, active management, general anesthesia, and emergent $\mathrm{C} / \mathrm{S}$ were found to be significant independent predictors of postpartum anemia, and (4) risk score $>-4$ was found to be a predictor for postpartum anemia with a sensitivity of $73.7 \%$ and specificity of $81.1 \%$, and risk score $>-4$ increases the risk of postpartum anemia approximately 12 times.

Data in the literature about anemia at the postpartum period are not enough to make an accurate comment on its prevalence in the general population. This is because there is not a standardized protocol for screening anemia at the postpartum period ${ }^{[15]}$. However, in a study from Spain, the prevalence of anemia after the birth of a child was reported as 29\%, meaning almost 1 out of each 3 patients discharged from the hospital had anemia [13]. In addition, in another study evaluating prevalence and risk factors for early postpartum anemia, a prevalence of $22 \%$ was given ${ }^{[6]}$. In the study by Milman et al. ${ }^{[1]}$ in 2011, the risk of postpartum anemia was found to be decreased when prepartum iron supplements were taken, and it was found that in the non-supplemented group, the prevalence of anemia was $24 \%-50 \%{ }^{[7]}$. This ratio was $14 \%$ in the supplemented group $^{[1]}$. However, in developing countries, the prevalence of postpartum anemia is as high as $70 \%-80 \%{ }^{[1,7]}$. Although 
our results displayed a lower prevalence than those of developing countries, it is still higher than those reported in the literature. Since our hospital is a tertiary center, most of the time the patients admitted to our clinic are being referred to our hospital for several reasons and do not have regular antenatal follow-up.

There are many risk factors that was defined for postpartum anemia in the literature. In accordance with the literature, in the present study, $C / S$, emergent $C / S$, presence of episiotomy, third- or fourth-degree perineal laceration, and application of general anesthesia were found to be more common among patients suffering from postpartum anemia. Since postpartum anemia is generally associated with severe blood loss during delivery and $\mathrm{C} / \mathrm{S}$, episiotomy and laceration of birth canal are variables reported as risk factors for postpartum anemia ${ }^{[1,6]}$. Similar to our study, in 2013, Kramer investigated the risk factors for severe postpartum hemorrhage and demonstrated that undergoing $\mathrm{C} / \mathrm{S}$ is associated with the increased risk of anemia ${ }^{[16]}$. Furthermore, Sheldon et al. ${ }^{[17]}$ showed that $C / S$ is a risk factor for blood transfusion during the postpartum period in the World Health Organization Multicountry Survey in 2014. In addition to these findings, we found that emergent $\mathrm{C} / \mathrm{S}$ was related with a nearly 19 times and general anesthesia with a nearly 3.9-fold increased risk for postpartum anemia in patients who underwent $C / S$.

Third- and fourth-degree perineal lacerations were also defined as one of the major risk factors increasing the risk of postpartum anemia independently from the presence of episiotomy ${ }^{[18,19]}$. In addition, Garrido et al. found that extensive perineal laceration involving the anal sphincter is a risk factor for postpartum anemia ${ }^{[13]}$.

In our study, perineal laceration has been identified as an independent predictor for postpartum anemia, and it has increased the risk of postpartum anemia approximately 7-fold. Moreover, episiotomy has been reported as an independent risk factor associated with postpartum anemia [16]. In our study, we found that episiotomy was related with postpartum anemia and had a nearly 5.4-fold increased risk for postpartum anemia. We suggest that this relationship could be due to the association between the presence of episiotomy and obstetric hemorrhage.

The mode of placental removal is another factor for postpartum anemia. Similar with data in the literature, we observed that active management of the third stage of labor is associated with less labor-related blood loss ${ }^{[20]}$. In the study by Garrido et al., [13] it was shown that active management of the third stage of labor is associated with a
$50 \%$ decrease in the risk of puerperal anemia. We found that active management of the third stage of labor had a protective effect for postpartum anemia consistent with the previous data.

It was reported in the literature that $23 \%$ of cases with postpartum anemia remain unidentified when patients having any of the five risk factors were selectively screened. Moreover, it was shown that when each risk factor was used separately to identify patients with postpartum anemia, none of them were shown to be reliable predictors since the sensitivity level of each was $<30 \%{ }^{[13]}$. In the present study, different from the studies performed in our population, we calculated the risk score by taking each OR as a multiplier of the corresponding variable, and we aimed to analyze the clinical value of each factor to identify patients who are under risk for postpartum anemia. By using this formula, it is expected to predict patients who are under increased risk for postpartum anemia with quite high sensitivity and specificity in our clinic. Therefore, to calculate such a risk score may be helpful in identifying patients who should probably develop postpartum anemia and also to develop a screening strategy for each clinic. We suggest that by using the formula risk score $=(5 \times$ episiotomy $)+(7 \times$ perineal

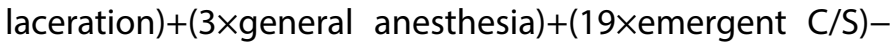
(11xactive management) in our population, we may determine patients who are at high risk for postpartum anemia with a high sensitivity and specificity. One of the disadvantages of this formula is that this model is based on a small sample-sized study population, and that further studies are required through larger sample-sized studies from different geographic regions of Turkey.

The limitation of the present study was that the iron deficiency status of women in the prepartum period and the iron supplementation status during pregnancy, which are other important risk factors of postpartum anemia, are unknown. Including these two aforementioned variables should possibly improve the ability of this calculated risk score in predicting patients who are under high risk.

However, our study has several strengths. First, in the Turkish population, data about the risk factors for postpartum anemia are quite limited. In this context, our findings may provide beneficial contributions to the literature. Second, exclusion of prepartum anemia among those patients is a unique feature of our study. Finally, different from other studies, a risk score was calculated for postpartum anemia development in our study. This scoring system maintains the advantage of increased reliability in predicting postpartum anemia as compared with using each of the risk factors separately. 


\section{Conclusion}

The results of the present study are complying with the previous data reported about the prevalence and risk factors of postpartum anemia. In conclusion, in our clinic, the prevalence of postpartum anemia is quite high, and so a non-selective screening program as has been suggested by the Ministry of Health could be applicable. However, determining patients under high risk is still important to be alert to prevent the short- and long-term morbidities associated with postpartum anemia as early as possible.

Ethics Committee Approval: Our study was conducted in accordance with the Declaration of Helsinki.

Peer-review: Externally peer-reviewed.

Authorship Contributions: Concept: B.D.; B.D.Ç.; Design: B.D.; Data Collection or Processing: B.D.C.; Analysis or Interpretation: B.D., B.D.Ç.; Literature Search: B.D.Ç.; Writing: B.D.

Conflict of Interest: None declared.

Financial Disclosure: The authors declared that this study received no financial support.

\section{References}

1. Milman N. Postpartum anemia I: definition, prevalence, causes, and consequences. Ann Hematol 2011;90:1247-53.

2. World Health Organization (1999). Reduction of maternal mortality: a joint WHO/UNFPA/UNICEF/World Bank statement. World Health Organization. Available at: http://www. who.int/iris/handle/10665/42191. Accessed May 24, 2019.

3. Potts $M$, Campbell $M$. Three meetings and fewer funerals--misoprostol in postpartum haemorrhage. Lancet 2004;364:1110-1. [CrossRef]

4. Tsu VD, Shane B. New and underutilized technologies to reduce maternal mortality: call to action from a Bellagio workshop. Int J Gynaecol Obstet 2004;85 Suppl 1:S83-93. [CrossRef]

5. Aggett P. Iron and women in the reproductive years. In: The British nutrition foundation's task force, editors. iron: nutritional and physiological significance, 1st edition. London: Chapman and Hall; 1995. p. 110-8. [CrossRef]

6. Bergmann RL, Richter R, Bergmann KE, Dudenhausen JW. Prevalence and risk factors for early postpartum anemia. Eur J Obstet Gynecol Reprod Biol 2010;150:126-31. [CrossRef]

7. Milman N. Anemia-still a major health problem in many parts of the world! Ann Hematol 2011;90:369-77. [CrossRef]
8. Frenkel Y, Shalev L, Shoham-Vardi I, Sergienko R, Wolak A, Sheiner E, et al. Early Postpartum Hemoglobin Less Than $10 \mathrm{~g} /$ $\mathrm{dL}$ Is Associated with Future Maternal Atherosclerotic Morbidity. J Womens Health (Larchmt) 2018;27:1257-62. [CrossRef]

9. Milman N. Postpartum anemia II: prevention and treatment. Ann Hematol 2012;91:143-54. [CrossRef]

10. Bodnar LM, Siega-Riz AM, Miller WC, Cogswell ME, McDonald T. Who should be screened for postpartum anemia? An evaluation of current recommendations. Am J Epidemiol 2002;156:903-12. [CrossRef]

11. Dar S, Vardi IS, Holcberg G, Reuveni H, Yerushalmi R, Katz M, et al. Do we need routine complete blood count following vaginal delivery? Int J Fertil Womens Med 2006;51:270-3.

12. Recommendation to prevent and control iron deficiency in the United States. MMWR Morb Mortal Wkly Rep 1998; 47:1325.

13. Medina Garrido C, León J, Romaní Vidal A. Maternal anaemia after delivery: prevalence and risk factors. J Obstet Gynaecol 2018;38:55-59. [CrossRef]

14. Doğum Sonu Bakım Yönetim Rehberi. T.C. Sağlık Bakanlığı Türkiye Halk Sağlığı Kurumu Kadın ve Üreme Sağlığı Daire Başkanlığı, Ankara, 2014. Sağlık Bakanlığı Yayın No: 925.

15. Barroso F, Allard S, Kahan BC, Connolly C, Smethurst H, Choo $\mathrm{L}$, et al. Prevalence of maternal anaemia and its predictors: a multi-centre study. Eur J Obstet Gynecol Reprod Biol 2011;159:99-105. [CrossRef]

16. Kramer MS, Berg C, Abenhaim H, Dahhou M, Rouleau J, Mehrabadi A, et al. Incidence, risk factors, and temporal trends in severe postpartum hemorrhage. Am J Obstet Gynecol 2013;209:449.e1-7. [CrossRef]

17. Sheldon WR, Blum J, Vogel JP, Souza JP, Gülmezoglu AM, Winikoff B; WHO Multicountry Survey on Maternal and Newborn Health Research Network. Postpartum haemorrhage management, risks, and maternal outcomes: findings from the World Health Organization Multicountry Survey on Maternal and Newborn Health. BJOG 2014;121 Suppl 1:5-13.

18. Petersen LA, Lindner DS, Kleiber CM, Zimmerman MB, Hinton AT, Yankowitz J. Factors that predict low hematocrit levels in the postpartum patient after vaginal delivery. Am J Obstet Gynecol 2002;186:737-44. [CrossRef]

19. Pergialiotis V, Vlachos D, Protopapas A, Pappa K, Vlachos G. Risk factors for severe perineal lacerations during childbirth. Int J Gynaecol Obstet 2014;125:6-14. [CrossRef]

20. Begley CM, Gyte GM, Devane D, McGuire W, Weeks A. Active versus expectant management for women in the third stage of labour. Cochrane Database Syst Rev 2015;CD007412. [CrossRef] 